\title{
Revisión sistemática: educación ambiental en la ciudadanía latinoamericana durante la covid 19
}

\author{
Leo Iván Arias Paullo \\ liapcusco@gmail.com \\ ORCID $0000-0002-5772-7038$ \\ Universidad Cesar Vallejo campus Lima Norte \\ Lima - Perú
}

\section{RESUMEN}

La educación ambiental (EA) como proceso de formación en valores culturales no muestra mayores avances, no más que las innumerables teorizaciones de académicos baluartes y autoridades con prioridades distintas al cuidado del medio ambiente, es así los comportamientos de gobernantes y gobernados en todas las esferas de la ciudadanía latinoamericana. Entonces, Con la pandemia de la Covid 19, de relevante crisis, se hace más evidente el descuido y desinterés, con escasos valores y poca conciencia social. Esto va dejando precedente, que ni en pandemia la educación ambiental emerge en cada ciudadano, obligando a cada país latinoamericano reevaluar sus políticas ambientales. Como objetivo se propone un análisis de las premisas conceptuales de la educación ambiental, se explica el enfoque de investigaciones revisadas, acompañado de una descripción del comportamiento de la ciudadanía latinoamericana en tiempos de pandemia, además de un estudio de conclusiones de las investigaciones revisadas. Estos conocimientos tienen, concepción descriptiva de contenidos, y desde un diseño bibliográfico; se ha estimado 150 hallazgos sometidos al método prisma, al final van a estudio 10 artículos de mayor relevancia y accesibilidad por características de educación superior en américa latina, que nos lleva a concluir que, el comportamiento de la ciudadanía en tiempos de pandemia no ha mostrado importantes evidencias de educación ambiental, por el contrario, hemos sido una sociedad que ha expuesto su propia vida desobedeciendo las determinaciones de sus gobiernos, entonces la poca conciencia humana debe ser reformada para evitar el peligro de la continuidad de la vida en el planeta.

Palabras clave: valores culturales; ciudadanía; ecosistema; eco-educación. 


\title{
Systematic review: environmental education in latin american citizens during covid 19
}

\begin{abstract}
Environmental education (EE) as a process of training in cultural values does not show major advances, no more than the innumerable theorizations of academic bastions and authorities with different priorities to care for the environment, this is the behavior of the rulers and the ruled in all spheres of Latin American citizenship. Then, with the Covid 19 pandemic, of relevant crisis, carelessness and disinterest, with few values and little social awareness, becomes more evident. This is setting a precedent, that not even in a pandemic does environmental education emerge in every citizen, forcing each Latin American country to reevaluate its environmental policies. As an objective, an analysis of the conceptual premises of environmental education is proposed, the approach of the reviewed research is explained, accompanied by a description of the behavior of Latin American citizens in times of pandemic, in addition to a study of the conclusions of the reviewed research. These knowledge have a descriptive conception of content, and from a bibliographic design; 150 findings have been estimated subjected to the prism method, in the end 10 articles of greater relevance and accessibility by characteristics of higher education in Latin America will be studied, which leads us to conclude that the behavior of citizens in times of pandemic has not shown important evidences of environmental education, on the contrary, we have been a society that has exposed its own life disobeying the determinations of its governments, so the little human conscience must be reformed to avoid the danger of the continuity of life on the planet.
\end{abstract}

Keywords: cultural values; citizenship; ecosystem; eco-education.

Artículo recibido: 02 Setiembre. 2021 Aceptado para publicación: 30 Setiembre. 2021

Correspondencia: liapcusco@gmail.com Conflictos de Interés: Ninguna que declarar 


\section{INTRODUCCIÓN}

América latina no ha sido la excepción de las pandemias suscitadas a lo largo de los años de existencia del planeta, es así que López et al., (2020), señalan que, nunca podría ser propicio ningún momento para la invasión de una pandemia que ocasiona tiempos sumamente preocupantes para la humanidad. Ciertamente, como en todos del mundo los países latinoamericanos, vuelven a sufrir una amenaza viral llamado el nuevo coronavirus SARS-CoV-2 que ha generado una crisis mundial, y en los países latinos las consecuencias son de catástrofe, obligándonos a confinamientos de acuerdo a determinaciones de las políticas de salud de cada país. Esta crisis de la Covid - 19, muestra dos vertientes, siendo medioambiental desde sus orígenes y de salud pública desde sus efectos (Pose, 2020). Las consecuencias de la pandemia, significan muerte, estancamiento de economías, pérdidas de trabajo, interrupción de empresas; siendo en efecto mayor decrecimiento de mayoría de los países latinos, destinados a empobrecimiento. De modo que, el hombre por su inconsciente actuar nos muestra una realidad ecosistémica, transformado por los daños causados como obra de sus manos; donde solamente en un tiempo largo podría recuperarse nuestra naturaleza (Conopoima, 2021). En este mismo sentido, y con una apreciación constructiva (Bolaños, 2020), alienta el fomento de los valores utilizando conocimiento científico para la consolidación del crecimiento sostenible al servicio de la humanidad.

Desde el mes de diciembre del año 2019, el comportamiento de la ciudadanía se ve alterada por la actual pandemia Covid - 19, donde la educación ambiental formadora de valores desarrolla habilidades y expone actitudes más allá de lo normal -forzadas-; diría desde las fuerzas de la naturaleza que nos han empujado a un comportamiento humano obligatorio de quedarnos en casa mientras, los espacios ocupados por muchos años como las playas, los parques, los ríos, los cerros y otros lugares, fueron devueltos por algún espacio de tiempo a los animales que ocuparon esos lugares a vista nuestra. Mastrocola (2021), precisa que, la naturaleza ha recuperado sus espacios donde los animales salvajes fueron vistos en ciudades como: Chile, Perú y España; pumas, gaviotas - delfines y jabalíes respectivamente, estuvieron entre parques, playas y calles. Consecuentemente, ante tanta contaminación y destrucción que nosotros mismos ocasionamos, podríamos resaltar como acción natural positiva, la recuperación del planeta aún solo signifique en tiempo pandémico. En este mismo orden Johnson et al., (2020), señalan que la ciudadanía 
en tiempos de Covid, asume su condición de ser social con expresión relevante de sus valores como solidaridad, unión, empatía y mejor conciencia social. Esto indica que, el coronavirus significa para el mundo un tipo de desastre donde la educación ambiental en orden de importancia debe coadyuvar en la mitigación como acción proactiva en esta nueva normalidad. (Ilyasa et al., 2020).

Munsell et al., (2020), dicen "quédate en casa" por qué es más seguro, lo que significa una connotación emocional y de educación ambiental que permite la existencia de la ciudadanía en el mundo entero para evitar contaminarse. Por esta razón, la ciudadanía se ha visto comprometida a tener un comportamiento direccionado por la pandemia en aspectos como el uso racional de los alimentos, el consumo de éstos de acuerdo a valores nutricionales y fortalecimiento inmunológico para hacer frente al virus. Consecuentemente, nuestras vidas están sometidas al cambio, y la preocupación es si seremos mejores seres humanos cuando pase esta amenaza mundial, o simplemente dejaremos pasar esta oportunidad de crecimiento; de reformarnos en educación ambiental (Quay et al., 2020). A esto se suma la inacción de funcionarios que conlleva a mayor preocupación, resultando que en más de seis países de américa latina gerentes públicos muestran incapacidad por dependencia de voluntad política, presupuestos insuficientes, falta de autonomía y ausente participación ciudadana (Sainz y Martínez, 2021).

Las entidades de gobierno nacional de todos los países latinos, se han encargado de difundir comportamientos adecuados para la ciudadanía en el manejo de los desechos compactos con adecuado recojo hasta la colocación final. Entonces, con enfoque crítico en nuestro propio actuar diario e interdependiente, debemos ser promotores de cultura y naturaleza con cambio en perspectiva (Cevallos y Úcar, 2019). Es así que, En temas de contaminación la ciudadanía se ha preocupado mucho más para evitar contagiarse y consecuentemente la desinfección de manos, de los ambientes de vivencias, del uso innecesario del plástico se muestra como cambios de actitudes en este proceso de aprendizaje o convivencia en tiempos de Covid. El enfoque de Romero et al., (2021), fortalecen lo que venimos afirmando, entendiendo a las manos como una parte del cuerpo expuesto a la contaminación, potencial medio de transporte viral y llevados a la boca, nariz u ojos somos víctimas de contagio.

Desde la propuesta de revisión de literatura científica, entendemos que, la educación ambiental debe ser una constante política de gobiernos, con posibilidades de periódicas 
evaluaciones para mejoras continuas en beneficio de la humanidad y sostenimiento de una sociedad culta eco-ambientalista, de suerte que en tiempos de Covid, amerita un análisis de premisas conceptuales, explicando con claridad el enfoque de las investigaciones de autores que han dedicado su tiempo a proponer saber eco-educativo producto de comportamientos ciudadanos en américa latina, que, a manera narrativa, una descripción coherente nos da entendimientos o conceptualizaciones valorables comparativas. En tanto Činčera et al., (2020) con todo y lo anterior, admiten que la sociedad dominante desarrolla prácticas de enfoque crítico donde la educación ambiental nunca podría estar libre de valores, y entendiendo esta razón fijemos retos para los países de América Latina, miremos países europeos y los desarrollados asiáticos, aprendamos educación ambiental de otras experiencias de vivencias equilibradas.

Los relatos muestran preocupación de las personas por el cuidado y protección ambiental, consiguientemente un análisis de las conclusiones permitirá a toda luz como enfocan las distintas investigaciones consideradas en la presente exploración académica. Así mismo, La evaluación del impacto se hace complejo porque predeterminar resultados en el ejercicio de educación para el desarrollo es inesperado (O’Flaherty y Liddy, 2018). De otro lado, al retomar el enfoque central de educación ambiental en la problemática de escases de agua, Ruiz y Diez (2021), sentencian que la mayoría de la población, nos mostramos inconscientes e insensibles sobre el cuidado del agua, promoviendo consecuencias de mayores escases a falta de educación ambiental y conciencia ciudadana. En este entender, la educación ambiental desde la presente investigación, propone analizar la relevancia que sostienen otras pesquisas de ciencia, en relación al comportamiento ciudadano y su accionar pro-ambiental en américa latina durante la pandemia Covid- 19. Concluyendo decimos que, metodológicamente las características en este artículo son de revisión sistemática narrativa que describe una exhaustiva revisión clasificada en concordancia con López de Parra et al., (2020), consideramos aportes cognoscitivos desde la interdisciplinaridad, para constituir una valiosa propuesta de atención; a la problemática ambiental de mejores resultados eco-formativos.

\section{ESTRATEGIAS METODOLÓGICAS O MATERIALES Y MÉTODOS}

El objetivo del artículo es analizar las premisas conceptuales de la educación ambiental, explicar el enfoque de las investigaciones revisadas, describir el comportamiento de la ciudadanía y analizar las conclusiones de las pesquisas. Se debe identificar conciencia 
ambiental producto de medición de educación ambiental en la ciudadanía latinoamericana (Acosta et al., 2020).

Realizada la revisión sistemática de artículos, la presente investigación se somete a criterios con enfoque en variables relacionadas a la base de datos, donde la principal temática; es educación ambiental, sin dejar de considerar el parámetro temporal durante la pandemia de la Covid 19, sosteniendo en la estrategia de trabajo importantes consideraciones, como medio ambiente, conciencia ambiental, valores, políticas y salud pública. En esta misma concepción, Gonzales et al., (2021) señalan que, el estudio metodológico de objetivos claros en políticas ambientales es para salvar el planeta con los aportes de la ciencia y tecnología basado en los ODS de cara al 2030. Además, los principios de revisión sistemática con una técnica de análisis de contenidos deben sostenerse en trabajos de publicaciones indexadas para un aporte significativo a la ciencia (Toscano et al., 2019).

Las principales ideas obtenidas de investigaciones en las bases de datos, han sido seleccionadas metódicamente en los de acceso libre: Dialnet, Google Académico, Redalyc, Ingentaconnec, Eric, Latindex y Scielo, así como de documentos oficiales de políticas ambientales; con la finalidad de analizar la conciencia conductual y cultura de la ciudanía latinoamericana durante la pandemia. Calderón y Caicedo (2019) dicen: Es importante considerar criterios y variables para identificar información primaria a lo que complementan Alvarado y Méndez (2021), quienes entienden la metodología de una investigación, en el fortalecimiento con fuentes oficiales de indicadores de impacto. La educación ambiental es transformadora de acciones humanas que busca un cambio de comportamiento para alcanzar los objetivos de desarrollo sostenible, donde la metodología de estudio es el aporte de consistencia del investigador (Acosta et al., 2020). El presente estudio expone, análisis y procesamiento de la información, el mismo que coincide en cierta medida con (Tramullas, 2020), quien afirma que, para conocer los fundamentos teóricos de las investigaciones objetos de estudio, e identificar nuevas tendencias, necesitamos analizar resultados con técnicas de rentabilidad académica en pro de la ciudadanía global. Siendo así, estos conocimientos de revisión tienen, concepción descriptiva de contenidos, y desde un diseño bibliográfico; se ha estimado 150 hallazgos sometidos a filtros de acuerdo con el método prisma, quedando al final 10 artículos de mayor relevancia y accesibilidad por características en estudios de educación superior en 
américa latina, todos, vinculados a los objetivos, teniendo en cuenta una revisión sistemática que implique el uso de un método metanalítico a manera de hoja de ruta, con fundamento visualizable en un potente informe final (Moher, et al., 2015).

Figura 1. Proceso de revisión con método Prisma.

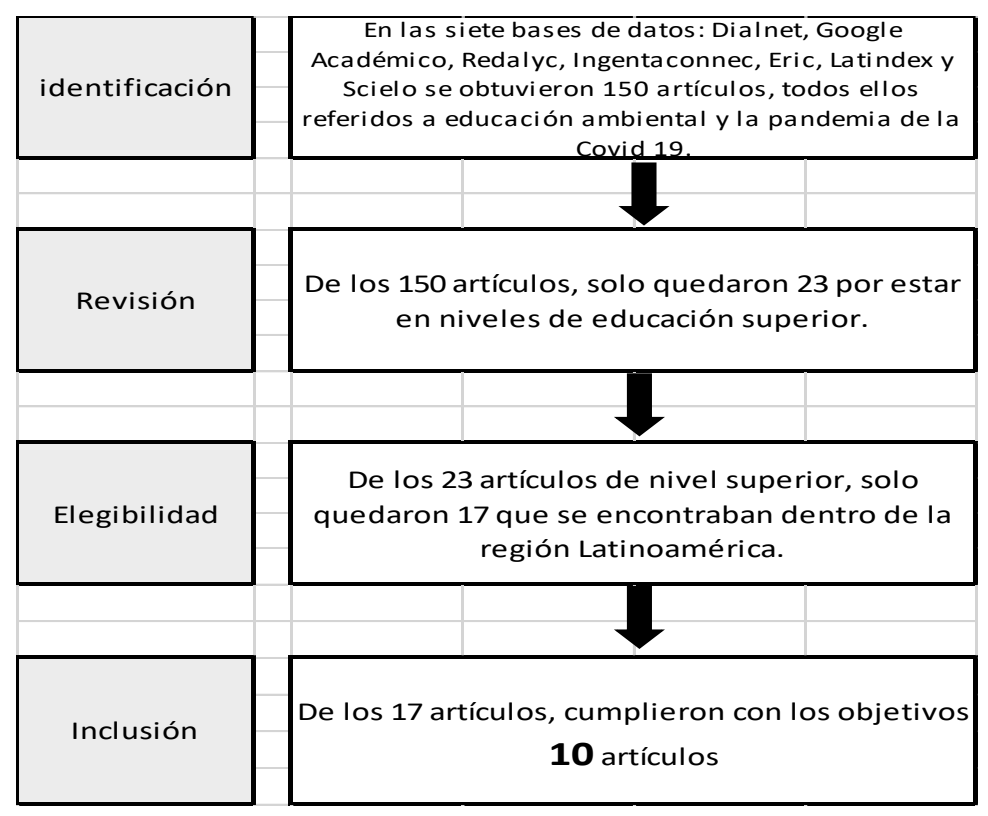

Tabla 1. Resultado de clasificación en repositorios

\begin{tabular}{|c|c|c|c|c|c|c|c|c|}
\hline Repositorio & Código & Combinación de búsqueda & Resultados & Temática & Región & Accceso & Objetivos & $\begin{array}{c}\text { Artículos no } \\
\text { repetidos }\end{array}$ \\
\hline Dialnet & A1 & Educación Ambiental & 31 & 2 & 1 & 1 & 0 & 0 \\
\hline $\begin{array}{c}\text { Google } \\
\text { Académico }\end{array}$ & B1 & Educación Ambiental & 62 & 10 & 8 & 5 & 5 & 5 \\
\hline Redalyc & C1 & Educación Ambiental & 24 & 1 & 1 & 1 & 1 & 1 \\
\hline Ingentaconnec & D1 & Educación Ambiental & 5 & 0 & 0 & 0 & 0 & 0 \\
\hline Eric & E1 & Educación Ambiental & 19 & 8 & 6 & 6 & 4 & 4 \\
\hline Latindex & F1 & Educación Ambiental & 4 & 1 & 1 & 1 & 0 & 0 \\
\hline Scielo & G1 & Educación Ambiental & 5 & 1 & 1 & 1 & 0 & 0 \\
\hline TOTAL & & & 150 & 23 & 17 & 15 & 10 & 10 \\
\hline
\end{tabular}

La tabla 1 explica el proceso de selección, donde la combinación de búsqueda nos permite obtener 150 artículos. Considerando la temática "educación ambiental", la región y objetivos, seleccionamos 10 estudios.

2, han sido afectadas no solo las personas debilitadas sino ciudadanos aparentemente fuertes y sanos. Estamos respirando aire turbio, y esto nos hace entender que, nuestro planeta se recupera con declaratoria de emergencia mundial para una obligatoria educación ambiental desde la disposición de gobiernos que promuevan tener biodiversidad protegida para una calidad de vida sostenible con grandes esperanzas para las generaciones venideras (Rojas, 2021). 
Para López de Parra et al., (2020), los aportes cognoscitivos desde la interdisciplinaridad, de cara a la problemática ecológica propicia resultados de conciencia ambiental, pudiendo demostrarse tal aseveración, desde una medición en la ciudadanía latinoamericana (Acosta et al., 2020). En este mismo orden, Gonzales et al., (2021) dicen, el estudio metodológico de objetivos claros en políticas ambientales, es para salvar el planeta, a esto Quintero y Solarte (2019), plantean estudiar la realidad ambiental desde distintos ángulos del conocimiento, a lo que consideramos y coincidimos, se aplique métodos analíticos interdisciplinarios y transdisciplinarios, con la finalidad de fomentar una educación ambiental no solo ajustada a las necesidades de una comunidad sino de percepción global (Calderón y Caicedo, 2019).

\section{Premisas conceptuales de la educación ambiental}

Gonzales et al. (2021), indican que las políticas de educación ambiental son los pilares básicos para la formulación de estrategias de metas de desarrollo sustentable en la diversidad de esferas sociales de América Latina, mientras, Castromil et al. (2020) precisan que (EA); se relacionan con la educación y el desarrollo humano como factores básicos. Por lo tanto, la investigación nos conduce a entender el comportamiento ciudadano latinoamericano parametrado en coyuntura pandémica, No obstante, es importante conocer que políticas se están implementando actualmente en los países de América Latina para examinar su contribución a favor de la población en estricto orden a cumplir la meta 2030 de los objetivos de desarrollo sostenible. Por otro lado, López et al.(2020) indican que los efectos directos de la pandemia y sus medidas de gestión incluyen una reducción significativa de la actividad económica y un aumento del desempleo, Aparecida et al. (2019) ratifican que esto sucede; mostrando un impacto en las condiciones sociales y la pobreza, donde las consecuencias ambientales pueden ser más inciertas. Quintero y Solarte (2019) argumentan que promover desarrollo sostenible de la región, es para lograr las diferentes interrelaciones entre los objetivos sociales, económicos y ambientales.

Entre muchas premisas, la educación ambiental fue abordado por un conjunto de editores de la revista australiana "educación ambiental y al aire libre", quienes reconocen los entornos naturales como fuentes para la satisfacción humana, sin embargo, resaltan que las desigualdades por razones socioeconómicas restringen a un sector importante de la población, constituyendo un desafío para la (EA) tanto que permita a todos disfrutar de 
bienestar natural (Quay, et al., 2020). Mientras para Ruiz y Diez, (2021), la conceptualización del tema en estudio, parte por valorar a la ciudadanía; a aquellos que luchan por las grandes minorías, a los que están del lado protector de la naturaleza aún con uso de tecnologías, donde la globalización capitalista excluya de si, su radicalismo despiadado potenciando valores culturales de apoyo directo a comunidades para un futuro seguro y eco-ambiental. En igual importancia Salas, (2020) afirma que la tecnología limpia genera desarrollo integral que busca el cuidado y protección ambiental, ésta viene desde los años 70 y recién para los 90 se entiende que, el funcionamiento de las empresas eco-amigables, empiezan a tener mayores niveles de rentabilidad, que al inicio los costos de los productos son elevados que de a poco tienen público consumidor, sin embargo, en estas circunstancias, el comportamiento de empresarios antiéticos preocupa por que oferten los mismos productos a precios menores. Consiguientemente nos damos cuenta que se requiere de un trabajo sostenido sumamente especializado para fomentar el sentido de cuidado y protección desde una educación ambiental (Salas, 2021).

\section{Enfoque de las investigaciones revisadas}

En la revisión, se presenta una variedad de enfoques, donde todos coinciden en propiciar políticas contundentes para lograr una ciudadanía responsable, de principios y valores, aun cuando unos tengan sus apreciaciones de la educación ambiental como disciplina y otros como un campo, podemos concretar que, la (EA) es un escenario amplio de conocimientos que nos permite plantear posturas sin alejarnos de la investigación en el contexto educativo.

De los 10 estudios se obtuvieron resultados; de las intervenciones realizadas dentro de instituciones, tomando como muestra estudiantes en diversas disciplinas, incluidas ciencias sociales, salud e ingeniería. Los estudios son tomados de diversas fuentes de revistas indexadas, algunos de estas investigaciones utilizaron softwares y herramientas tecnológicas, que les facilitó una revisión minuciosa y verídica de los artículos revisados, otros artículos explican las causas y peculiaridades de esta pandemia causado por virus Covid-19; desde diversas perspectivas como el punto de vista médico, sanitario, biológico, cultural y estructurales, todas con enfoque educativo y ambiental. Como Conopoima (2021) refiere la importancia sobre el rol del medio ambiente en este tiempo de pandemia, llamando a una reflexión sobre el impacto de la misma. De igual manera, López et al. (2020) realizaron un análisis sobre las consecuencias de la Covid-19 en el 
impacto del medio ambiente teniendo en cuenta los objetivos del desarrollo sostenible (ODS).

Una mirada a quienes son parte de un gobierno, nos lleva a entender el rol que cumplen éstos, y desde ésta época pandémica se ve desafíos que no hemos podido superar por sistemas dominantes de políticas nacionales y locales impropias; donde las autonomías de los funcionarios están sometidas a las autoridades de turno. Estas inacciones de hoy, impactarán en el futuro, y la educación ambiental deberá ser reevaluada en un contexto de variedad de pensamientos y experiencias para conectarnos, nuevamente con nuestro ecosistema (Sainz y Martínez, 2021; Quay et al., 2021). La concientización, va en crítica a la inoperancia de las autoridades, así como a los ciudadanos destructores y sin valores, reflexión que tiene valía para un mejor cuidado y protección de nuestro planeta (Salas, 2021). De forma similar Perales, (2020), enfoca su estudio atribuyendo que, los medios de comunicación desarrollan factores como agenda ambiental, informa temas ambientales para una audiencia persuadida, actúa como una fuente de valores y comportamientos, pudiendo los responsables políticos optimizar educación ambiental masiva con el uso de estas herramientas hoy denominadas cuarto poder.

Las investigaciones focalizadas en este trabajo muestran el comportamiento ciudadano; los casos de contagio por Covid 19 por efectos de la pandemia y entre sus factores revisa cuantitativa y cualitativamente la variable ambiental entendiendo como un vector pandémico, así como la tardía toma de decisiones de políticas públicas sanitarias por desconocimiento, afectando a las poblaciones de escasa educación ambiental (Alvarado y Méndez, 2021). Mientras Pose, (2020), remarca su estudio en una teorización de los años 70, propone "la bioética" como un concepto para su globalización en busca de la prosecución de la vida humana en la tierra, sin dejar de preservar los ecosistemas en su amplia biodiversidad, para lo que debemos unirnos por una transformación producto de pensamientos estratégicos. En definitiva, varios autores evalúan los efectos económicos y sociales como consecuencias de la Covid 19, donde el comportamiento humano en América Latina, va dejando serias consecuencias que repercuten en los ODS. La contaminación del aire, deforestación que contribuye a una crisis sanitaria, y otros desastres naturales, se deben regular con pertinente educación ambiental, evitando comportamientos impropios e intervenciones de políticas públicas de corto plazo (López, et al., 2020). 


\section{3.- El comportamiento de la ciudadanía en tiempos de pandemia.}

Enfocados en la problemática ambiental de nivel mundial y ahora centrados en Latinoamérica, entendemos que solo por el sendero de la educación podríamos establecer mejores condiciones de vida armónica de hombre y naturaleza, consiguientemente el comportamiento humano post pandemia tiene que ceñirse más al cuidado ambiental desde una conciencia humana, sabiendo que, los efectos económicos y sociales podrían conllevar a consecuencias peores de las que nos encontramos, Martínez (2019), pero a la vez ésta apertura discusión por la contaminación y otras de carácter ambiental en américa latina (López et al., 2020).

Como premisa de análisis, se debe considerar a la educación ambiental en una estrecha relación con el logro de los objetivos de desarrollo sostenible (ODS). Consiguientemente el comportamiento humano post pandemia tiene que ceñirse más al cuidado ambiental desde una conciencia humana, sabiendo que, los efectos económicos y sociales podrían conllevar a consecuencias peores de las que nos encontramos, pero a la vez ésta, apertura discusión por la contaminación y otras de carácter ambiental en américa latina (López, 2020). Mientras Conopoima (2021), hace un llamado a la reflexión desde dos tópicos significativos; que propicia comportamiento ciudadano, entendiendo el medio ambiente, como un conjunto de elementos y la Covid como una enfermedad infecciosa de factor alterante en el ser humano que genera un desmedro en la dinámica a nivel mundial. Mirando con mucha preocupación, Pose (2020) habla de los peligros de la continuidad de la vida en el planeta e interroga sobre, qué tipo de cambios serían necesarios en el accionar del hombre bioético; la misma que constituye -bioética la ciencia de la vida-. A todo esto, es importante decir que la pandemia de la Covid 19, repercute también y con alta incidencia en el factor económico de los países, haciendo que las políticas ambientales contribuirán mejor en tanto se planteen incorporación de nuevas normas de retos ambientales (Gonzales, 2021).

Proponer análisis de educación ambiental y la Covid 19, es hablar del comportamiento del ser humano latinoamericano, quien a lo largo de los años se ha mostrado indolente o simplemente desinteresado en sostener convivencia con su entorno natural, ahora y con ésta pandemia se hace evidente la carencia de conocimientos, para una correcta toma de decisiones ante la problemática de la salud, entendiendo que el sistema educativo en Latinoamérica habría olvidado sus prioridades. Así vivimos sin educación para la vida en 
supervivencia ambiental (Alvarado y Méndez 2021; Martin, 1994). A esto surge una propuesta interesante para mejorar el comportamiento humano, Perales (2020) dice: El uso correcto de los medios de comunicación podría reforzar la educación ambiental, habiéndose constituido como un potente facilitador por el consumo masivo de la ciudadanía y las distintas opciones que ofrece la internet. El fomento de las actitudes y aptitudes interrelaciona al hombre con su cultura y el medio ambiente, donde la educación ambiental debe contribuir a la protección ecosistémica, pero a la vez requiere de un trabajo especializado (Salas, 2021). En este mismo trayecto de educación innovadora, se debe propiciar mejores ciudadanos de pensamientos ambientalistas de enfoque al cambio de hábitos con la ayuda de la tecnología y hacer, por ejemplo, buen uso y consumo del agua por ser un recurso fundamental para el desarrollo y preservación de la vida (Ruiz y Diez, 2021).

La ciudadanía se comporta como quiere, y como mejor está educada, su aprendizaje es lento y hasta coyuntural, en tiempos de covid ha mejorado algo, pero no lo suficiente para entender que destruye su planeta. Todas las literaturas enfocan deficiencias en las formas de educar y la poca disposición a aprender (Sainz y Martínez, 2021).

\section{4.- Análisis de conclusiones enfocadas en educación ambiental}

La educación ambiental debe propiciar conocimientos necesarios en un afán de entender la complejidad de comportamientos y prácticas correspondientes a políticas públicas ambientales bien diseñadas (Rojas, 2020), lo peor del caso se entiende en las proyecciones económicas de crisis nunca antes vistas, que se vaticina para los países del mundo y principalmente a los de menor economía en Latinoamérica porque estamos viviendo una falsa dicotomía entre objetivos económicos sociales y ambientales (López, 2020). La reducción de la emisión de gases, de hecho, propicia un favorable cambio climático, se espera que el acuerdo de París en el contexto del Convenio Marco de las Naciones Unidas extermine con el mal uso del hombre sobre los recursos naturales e indebido manejo de elementos tóxicos. No esperemos otra Covid para disminuir contaminación (Conopoima, 2021). Es así que Pose (2020), concluye en que el cambio educativo y cultural enfrente la crisis medioambiental, además, sea oportunidad para mostrarnos frente la Covid ampliando el campo de acción de la bioética.

Gonzales et al., (2021), puntualiza su investigación en la importancia que se debe admitir la promoción de educación ambiental desde estudios iniciales del ser humano y durante 
su existencia, dándole formación intercultural para la preservación de su identidad y formación en integridad haciendo del ser reflexivo y protector de la naturaleza, mientras Alvarado y Méndez (2021) concluyen su trabajo científico, exponiendo el comportamiento de los ciudadanos de municipalidades donde los que tienen menos educación ambiental, se evidencia mayor contagio de la Covid 19, además expresan su preocupación por la reactivación económica y el comportamiento ciudadano que por desesperación, falta de educación y conciencia no atiendan las recomendaciones técnicas y científicas. Fortalecen lo dicho Salas, (2021); Gonzales et al., (2021), los que afirman que, la educación ambiental es forjadora de mejores ciudadanos responsables y proambientalistas donde la formación temprana contribuirá a la sostenibilidad, donde la (EA) mire el todo y no sólo las partes; sin descartar ningún escenario como un barrio o una calle en una acción transformadora de actitudes y aptitudes (Calderón y Caicedo. 2019).

En este análisis, es importante destacar, la ausencia de activismo por el cambio global; como resultado del aprendizaje en estudios revisados. La educación ambiental tiene como objetivo trabajar hacia acciones para un cambio social justo y sostenible (O'Flaherty y Liddy, 2018). Sin embargo, ninguno de los artículos citados aquí examinó aspectos de la acción y el activismo como parte de la intervención educativa o como parte del proceso de evaluación. Esto posiblemente se deba a la forma de pregunta de investigación formulada, pero es conclusión constituye una ausencia notable. Evaluar el conocimiento y la comprensión de la justicia global por parte de los jóvenes puede ser más sencillo en términos de su adquisición cognitiva, pero evaluar sus comportamientos y acciones para la justicia social, y sus valores y actitudes subyacentes, y con transversalidad académica es mucho más complejo (Núñez, et al., 2021) La acción para un cambio global justo y sostenible puede ir desde generar una mayor conciencia a través de la escritura de cartas o las redes sociales hasta el activismo personal de los consumidores, y desde presionar a los políticos locales, hasta participar en consultas de políticas nacionales, y precisando, es imposible posible negar lo evidente, la necesidad de formación ciudadana.

\section{CONCLUSIÓN O CONSIDERACIONES FINALES}

El tiempo de pandemia, paradójicamente constituye una acción natural positiva para la recuperación del planeta, y en orden de importancia la educación ambiental coadyuva en la mitigación proactivamente para una ciudadanía que supere comportamientos 
inadecuados, aprovechando sus temores y una tenue muestra de empatía y valores para ser mejores seres humanos.

No han sido suficientes las determinaciones de comportamientos para prevenir el contagio de la Covid 19, menos son efectivas las prácticas eco-ambientales como el tratamiento de los residuos sólidos o el cuidado y consumo adecuado del agua. Enfoques que han sido visualizados por los artículos revisados, y sus autores han entendido que el problema no solo es de autoridades de turno que promuevan cultura y naturaleza en el contexto de educación ambiental, sino de ciudadanía desinteresada e inconsciente.

La educación ambiental como constante política de gobiernos, debe enmarcar periódicas evaluaciones, proponiendo mejoras continuas para la sostenibilidad en pro de la sociedad culta eco-ambientalista, entendiendo los valores en todas sus dimensiones que permitan fijar retos para los países latinoamericanos, sosteniendo una mirada en toda dirección, aprendiendo de experiencias sostenibles de países europeos, asiáticos y de los propios latinoamericanos que tienen sus experiencias por enseñar.

La revisión sistemática narrativa, es la característica del artículo, la misma que hace una descripción exhaustiva a las premisas conceptuales que valoran y consideran como pilar básico para la formulación de estrategias y metas de desarrollo sostenible a las políticas de educación ambiental, haciendo que, entendamos mejor el comportamiento ciudadano latinoamericano en esta coyuntura pandémica; que precisa consecuencias ambientales inciertas, para lo que se debe promover desarrollo sostenible interrelacionando objetivos sociales, económicos y ambientales. Es más, entendiendo que las desigualdades socioeconómicas restringen a un sector importante de la población que también debería beneficiarse del bienestar natural. En este orden se debe valorar a quienes luchan por los más desfavorecidos, fortaleciendo a esos pocos protectores del medio ambiente, a los que practican tecnología limpia para generar desarrollo integral.

El comportamiento de la ciudadanía latinoamericana en tiempos de pandemia no ha mostrado grandes evidencias de educación ambiental, por el contrario hemos sido una sociedad que ha expuesto su propia vida desobedeciendo las determinaciones de sus gobiernos, entonces la poca conciencia humana debe ser reformada para evitar el peligro de la continuidad de la vida en el planeta, con buenas practicas bioéticas con nuevas normas de retos ambientales, además apropiándonos del uso de las herramientas comunicativas como un potente facilitador para la difusión de educación ambiental; 
sabiendo que hoy por hoy tiene un consumo masivo desde las redes sociales de la internet, e inclusivo la radio, la prensa escrita y la televisión.

Las investigaciones en sus conclusiones, señalan que se debe propiciar la implementación de políticas contundentes para lograr ciudadanía responsable de principios y valores, donde se expone dos apreciaciones sobre educación ambiental, una como disciplina y la otra como un campo de estudio, mientras las mismas investigaciones coinciden su entendimiento en que, la educación ambiental es un escenario amplio de conocimientos y planteamientos sostenibles, de posturas que buscan solucionar problemas para el bienestar de la humanidad.

En un contexto de medidas de pandemia por la Covid-19, la incursión de los nuevos modelos de Gestión Pública en el contexto de política educativa, la práctica y exigencia evidencian una sólida justificación para el cambio educativo, como la inclusión de temas de desarrollo global y desarrollo sostenible. Entre tanto, se observó que existe una limitada conciencia en cuanto al comportamiento de los pobladores en Latinoamérica, esto debido a diversos factores que pueden ser culturales, estructurales, sociales, de gobernabilidad, legal y otros. El impacto se conceptualizó como: cambio en el conocimiento, las habilidades, las actitudes, la ética y las acciones que surgen, incluidos los resultados de las mediciones tanto duras como blandas, desde los exámenes y las pruebas de conocimiento hasta las medidas de ética y valores, donde muchos estudios informan resultados estadísticamente significativos y otros destacan los resultados positivos de sus intervenciones educativas. Sin embargo, de esta revisión han surgido una serie de cuestiones, en particular cuestiones de epistemología, metodología y pedagogía, dejando las cuestiones epistemológicas claras a partir del proceso de revisión.

\section{LISTA DE REFERENCIAS}

Acosta, P., Queiruga, A., Hernández, A., y Acosta, L. (2020). Environmental Education in Environmental Engineering: Analysis of the Situation in Colombia and Latin America. Sustainability, 12(18), 2 - 14. doi:https://doi.org/10.3390/su12187239

Alvarado, C., y Méndez, L. (2021). Determinación del índice de impacto del COVID-19 en El Salvador, por medio de la relación demográfica, ambiental y epidemiológica. Población y salud en Mesoamérica, 18(2), 1 - 23. doi:http://dx.doi.org/10.15517/psm.v18i2.42242

Aparecida, M., Gargaro, V., Aparecida de Souza, E., \& Bim, F. (2019). Historical 
Evolution of Scientific Initiation Projects in the Area of Environmental Education. Interdisciplinary Journal of Environmental and Science Education, 15(1), e02205. https://doi.org/10.29333/ijese/6290

Bolaños, G. (2020). La formación en valores ante la crisis del COVID-19: retos para la Educación Media Superior en México. FORHUM International Journal of Social Sciences and Humanities, 2(3), 22 - 33. doi:https://doi.org/10.35766/jf20233

Calderón, S., y Caicedo, C. (2019). Educación Ambiental: Aspectos relevantes de sus antecedentes y conceptos. Revista Ingeniería y Región, 22, 14 - 27. doi:https://doi.org/10.25054/22161325.2565

Castromil, A. R., Rodríguez, R., y Garrigós, P. (2020). The political agenda in the Spanish election of april 2019: Electoral programs, twitter, and electoral debates. Profesional de La Informacion, 29(2). https://doi.org/10.3145/epi.2020.mar.17

Cevallos, B., y Úcar, X. (2019). Educación Popular, Educación Ambiental y Buen Vivir en América Latina: una experiencia socioeducativa de empoderamiento comunitario. Revista semestral para animadores y educadores sociales(30), 1 26. Obtenido de http://quadernsanimacio.net/ANTERIORES/treinta/index.htm

Činčera, J., Johnson , B., Kroufek , R., y Šimonová , P. (2020). Values Education in Outdoor Environmental Education Programs from the Perspective of $\begin{array}{lll}\text { Practitioners. } & \text { Sustainability, } & 4700 .\end{array}$ doi:https://doi.org/10.3390/su12114700

Conopoima, Y. d. (2021). COVID-19 y medio ambiente: un llamado a la reflexión. Espí$\begin{array}{llllll}\text { ritu Emprendedor } & \text { TES, } & 5(1), & 29 & - & 44 .\end{array}$ doi:https://doi.org/10.33970/eetes.v5.n1.2021.233

Gonzales, M., Sanabria, F., Ríos, J., y Colina, F. (2021). Crecimiento económico y políticas ambientales en Latinoamérica. CIENCIAMATRIA, 7(1), 14 - 34. doi:https://doi.org/10.35381/cm.v7i1.461

Ilyasa, F., Rahmayanti, H., Muzani , M., Zajuli Ichsan, I., y Suhono, S. (2020). Environmental Education for Prevent Disaster: A Survey of Students Knowledge in Beginning New Normal of COVID-19. IJoASER, 2(3), 1 - 8. doi:https://doi.org/10.33648/ijoaser.v3i2.60 
Johnson, M., Saletti-Cuesta, L., y Tumas, N. (2020). Emociones, preocupaciones y reflexiones frente a la pandemia del COVID-19 en Argentina. Scielo , 25(1), 2447 - 2456. doi:https://doi.org/10.1590/1413-81232020256.1.10472020

Leiva-Cabrera, F. A. (2020). Educación Ambiental para el poblador del distrito de Casa Grande en el manejo de residuos sólidos urbanos entre julio a diciembre del año 2019. Arnaldoa, 27(1), 323-334. https://doi.org/10.22497/arnaldoa.271.27120

López, A., Vélez, M., Chavéz, C., Bejarano, H., Chimeli Ariaster, B., Féres, J., . . Viteri, C. (2020). COVID-19: impactos en el medio ambiente y en el cumplimiento de los ODS en América Latina. Revista Desarrollo y Sociedad(86), 104 - 132. https://doi.org/10.13043/DYS.86.4

López de Parra, L., García Capdevil, D., Balanta Martínez, V., y Agundez Rodríguez, A. (2020). La investigación en educación ambiental y deforestación: aportes para la formación Ambiental comunitaria para evitar la degradación de los bosques.

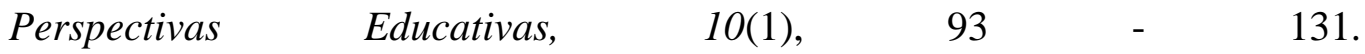
http://revistas.ut.edu.co/index.php/perspectivasedu/article/view/2387/1813

Martín, F. (1994). Educación ambiental: la educación para la vida. Revista Complutense

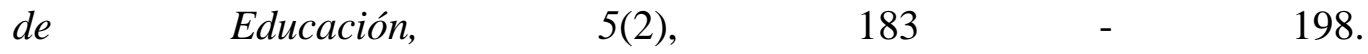
https://revistas.ucm.es/index.php/RCED/article/download/RCED9494220183A/ 17781

Martínez, M. (2019). Importancia de la educación ambiental. Revista Tecnológica, 17, 32. http://escuela13de18melian.blogspot.com/2017/05/calendario-ambiental-

Méndez, L., y Alvarado, C. (2021). Determinación del índice de impacto del COVID-19 en El Salvador, por medio de la relación demográfica, ambiental y epidemiológica. Pobalción y Salud en Mesoamérica, 18(2), 1 - 23. doi:https://doi.org/10.15517/psm.v18i2.42242

Moher, D., Shamseer, L., Clarke, M., Ghersi, D., Liberati, A., Petticrew, M., . . . PRISMA-P Group. (2015). Preferred reporting items for systematic review and meta-analysis protocols (PRISMA-P) 2015 statement. Systematic reviews, 4(1), 2 - 9. doi:https://doi.org/10.1186/2046-4053-4-1

Munsell, S., O’Malley, L., y Mackey, C. (2020). Coping with COVID. Educational Research: Theory and Practice, 31(3), $101 \quad$ - 109. https://files.eric.ed.gov/fulltext/EJ1274340.pdf 
Nuñez, G., Hayk , P., y Bejas , M. (2021). Enseñanza de la educación ambiental para el desarrollo sostenible en el Ecuador. Polo del Conocimiento, 6(6), 821 - 832. doi: $10.23857 /$ pc.v6i6.2789

O'Flaherty , J., y Liddy, M. (2017). The impact of development education and education for sustainable development interventions: a synthesis of the research. Environmental Education Research, 24(7), $1031 \quad$ - 1049. doi:https://doi.org/10.1080/13504622.2017.1392484

Page, M. J., McKenzie, J. E., Bossuyt, P. M., Boutron, I., Hoffmann, T. C., Mulrow, C. D., Shamseer, L., Tetzlaff, J. M., Akl, E. A., Brennan, S. E., Chou, R., Glanville, J., Grimshaw, J. M., Hróbjartsson, A., Lalu, M. M., Li, T., Loder, E. W., Mayo, E., McDonald, S., ... Moher, D. (2021). The PRISMA 2020 statement: An updated guideline for reporting systematic reviews. In The BMJ (Vol. 372). British Medical Journal Publishing Group. https://doi.org/10.1136/bmj.n71

Páramo, P. (2017). Reglas proambientales: una alternativa para disminuir la brecha entre el decir-hacer en la educación ambiental. Suma Psicológica, 24(1), 42-58. https://doi.org/10.1016/j.sumpsi.2016.11.001

Perales, J. (2020). Educación ambiental y medios de comunicación: revisión de la literatura y propuestas de intervención. Revista de Educación Ambiental y Sostenibilidad, 2(2), 2102. doi:https://doi.org/10.25267/Rev_educ_ambient_sostenibilidad.2020.v2.i2.2102

Pérez, N. R., Cleveland, M. R., Lleras, S. A., Cortés, N., y Cortés, E. (2019). Educación ambiental mediante la metodología aprendizaje-servicio: percepción de adquisición de competencias e impacto en la comunidad. Revista Universidad y Sociedad, 11(4), 154-162. https://orcid.org/0000-0002-2378-793X

Pose, C. (2020). COVID-19, salud públuca y medioambiente. EIDON(53), 64 - 76. doi:https://doi.org/10.13184/eidon.53.2020.64-76

Quay, J., Gray, T., Thomas, G., Allen, S., Morten Asfeldt, M., Andkjaer, S., . . Foley, D. (2020). What future/s for outdoor and environmental education in a world that has contended with COVID-19? Journal of Outdoor and Environmental Education(23), 93 - 117. doi:https://doi.org/10.1007/s42322-020-00059-2

Quintero, M., y Solarte, M. C. (2019). Las concepciones de ambiente inciden en el modelo de enseñanza de la educación ambiental. Entramado, 15(2), 130-147. 
https://doi.org/10.18041/1900-3803/entramado.2.5602

Rojas, J. (2021). Una revisión de la investigación en Educación Ambiental. Seres y Saberes, $9(1)$, 19

$-24$. http://revistas.ut.edu.co/index.php/SyS/article/view/2423/1853

Romero, J., Simaluiza, J., y Fernandez , H. (2021). Medidas de prevención para evitar el contagio por la COVID-19: de lo cotidiano a lo técnico-científico. Revista $\begin{array}{llllll}\text { Española de } & \text { Salud } & \text { Pública, } & 95(1), & 2 & -14 .\end{array}$ https://www.mscbs.gob.es/biblioPublic/publicaciones/recursos_propios/resp/revi sta_cdrom/VOL95/REVISIONES/RS95C_202104051.pdf

Ruiz, E., y Diez, M. (2021). Formación de ciudadanos ambientales mediante un curso sobre la sostenibilidad del agua utilizando TIC. Revista de Educación Ambiental

Sostenibilidad, $3(1)$,

1301. doi:https://doi.org/10.25267/Rev_educ_ambient_sostenibilidad.2021.v3.i1.1301

Sainz, J., y Martinez, A. (2021). Governance of urban green spaces across Latin America -Insights from semi-structured interviews to managers amid COVID-19. Centre for Environmental and Resource Economics (CERE), 1 - 36. doi:https://dx.doi.org/10.2139/ssrn.3782285

Salas, H. (2021). Educación ambiental y su contribución al cuidado y protección del ecosistema. Fides Et Ratio, 21, $229 \quad$ - 245. https://www.researchgate.net/publication/350438937_Educacion_ambiental_y_s u_contribucion_al_cuidado_y_proteccion_del_ecosistema

Toscano, A., Fuentes , D., y Fajardo , M. (2019). Sostenibilidad universitaria con enfoque en la educación ambiental: redes de colaboración y clúster temáticos de la producción científica mundial. Panorama Económico, 27(1), 60 - 84. doi:https://doi.org/10.32997/2463-0470-vol.27-num.1-2019

Tramullas, J. (2020). Temas y métodos de investigación en Ciencia de la Información, 2000-2019. Revisión bibliográfica. Profesional de laInformación, 29(4), 2 - 18. doi:https://doi.org/10.3145/epi.2020.jul.17 